\title{
Statin-Associated Muscle Adverse Events Update for clinicians
}

"Maha A. Al-Mohaissen, ${ }^{1}$ Martha J. Ignaszewski, ${ }^{2}$ Jiri Frohlich, ${ }^{3}$ Andrew P. Ignaszewski ${ }^{4}$

$$
\text { الأثار الجانبية المرتبطة بالعضلات لأدوية الستاتين }
$$

مها المحيسن، مارثا اجنشفسكي، ييري فرولك، أندرو اجنشفسكي

ABSTRACT: Statins are potent medications which reduce low-density lipoprotein cholesterol (LDL-C) levels. Their efficacy in cardiovascular risk reduction is well established and indications for their use are expanding. While statins are generally well tolerated and safe, adverse events are relatively common, particularly statinassociated muscle adverse events (SaMAEs), which are the most frequently encountered type of adverse event. Recent guidelines and guideline updates on SaMAEs and statin intolerance have included revised definitions of SaMAEs, incorporating new evidence on their pathogenesis and management. As SaMAEs emerge as a therapeutic challenge, it is important for physicians to be aware of updates on management strategies to ensure better patient outcomes. The majority of patients who are considered statin-intolerant can nevertheless tolerate some forms of statin therapy and successfully achieve optimal LDL-C levels. This review article discusses the recent classification of SaMAEs with emphasis on pathogenesis and management strategies.

Keywords: Hydroxymethylglutaryl-CoA Reductase Inhibitors; Hyperlipidemias; Hypercholesterolemia; Myopathies; Adverse Effects.

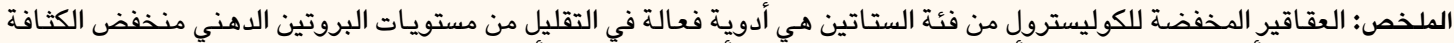
ارديال وفL-C)

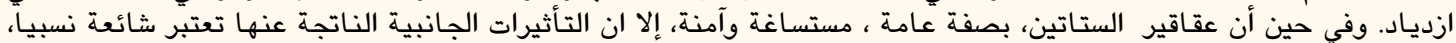

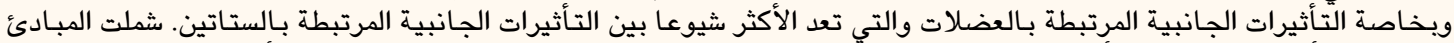

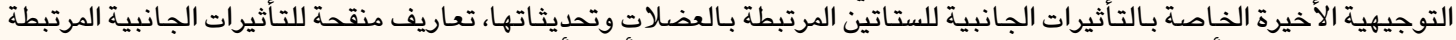

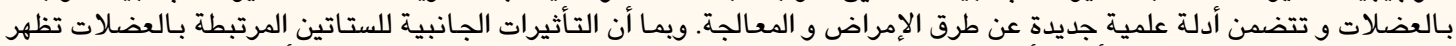

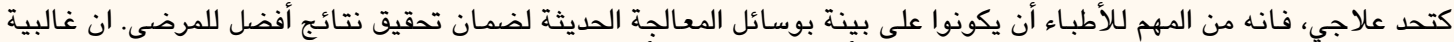

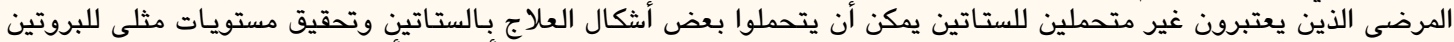

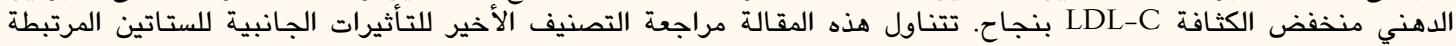
بالعضلات مع التركيز على إستراتيجيات الإمراض ووسائل العناون المعالجه.

الكلمات المفتاحية: مثبطات انزيم اتش ام جي-كو اي المختزلة؛ فرط شحميات الدم؛ فرط كوليستيرولِ الدم؛ الاعتلال العضلي؛ آثار سلبية.

$\mathrm{S}$ TATINS ARE A GROUP OF POTENT LOW-DENsity lipoprotein cholesterol (LDL-C)-lowering drugs. ${ }^{1}$ Their efficacy in improving cardiovascular morbidity and mortality is supported by a large body of evidence. ${ }^{2}$ Although statins are generally well-tolerated and safe, side-effects are relatively common, with muscular complaints occurring most frequently. ${ }^{3,4}$ In the majority of patients, these are mild and reversible; however, in rare cases, patients may develop more severe adverse effects. ${ }^{3}$ In clinical practice, the management of patients with statin-associated muscle adverse events (SaMAEs) has emerged as a therapeutic challenge among physicians seeking evidence-based LDL-C-lowering therapies. Recently, positive results from an international trial supported the use of non-statin drugs for the management of statin-intolerant dyslipidaemic patients and confirmed the "lower is better" LDL-C hypothesis. ${ }^{5}$ In addition, the introduction of proprotein convertase subtilisin/ kexin type 9 (PCSK9) inhibitors, although parenteral, offers a potentially strong alternative. ${ }^{6}$ In view of these data, the American College of Cardiology (ACC) Expert Consensus Decision Pathway was created to incorporate recent evidence on LDL-C-lowering agents in patient management to reduce the risk of atherosclerotic cardiovascular disease (ASCVD). ${ }^{7}$

Besides these advances in therapy, new guidelines and guideline updates have been issued on statinassociated adverse events in recent years. In 2015, the National Lipid Association (NLA) updated their 
2006 guidelines, redefining SaMAEs and providing recommendations on management. ${ }^{4}$ The original consensus statement of the Canadian Consensus Working Group (CCWG) for the diagnosis, prevention and management of statin-associated adverse effects and intolerance was updated in 2013 and 2016; these outlined the adverse effects of statins and reviewed recent evidence on the management of statinintolerant patients. ${ }^{8-10}$ The European Atherosclerosis Society (EAS) Consensus Panel issued a statement that focused specifically on the diagnosis and management of statin-associated muscle symptoms. ${ }^{11}$ It is important for clinicians to be aware of these recommendations and current management options based on recent trial results.

\section{Statin Intolerance and Adverse Effects}

Several definitions have been proposed for statin intolerance. ${ }^{3,9}$ The NLA defines statin intolerance as the inability to tolerate at least two statins, with one of them administered at the lowest starting daily dose and the other at any dose. ${ }^{3}$ This intolerance may manifest as symptoms, signs or laboratory abnormalities which negatively affect an individual's quality of life and lead to a decrease in dosage or discontinuation of the statin. These abnormalities must be temporally associated with statin therapy, resolve upon statin discontinuation and be reproducible by rechallenge. ${ }^{3}$ There is some ambiguity regarding the concept of the lowest dose for each statin drug. In the most recent CCWG consensus statement, Mancini et al. referred to the approved statin drug doses in their definition of statin intolerance. ${ }^{10}$ Intolerance to statins can be complete (intolerance to all statins at any dose) or partial (intolerance to certain statins at specific doses). The exclusion of other established predisposing factors to observed side-effects-including drugdrug interactions, untreated hypothyroidism and febrile illness-is a prerequisite for a diagnosis of statin intolerance. ${ }^{9}$

SaMAEs are reported by $5-29 \%$ of treated patients. ${ }^{11,12}$ Data from the Arabian Gulf on the prevalence and management of SaMAEs are currently lacking. Results from the Dyslipidemia International Study-Middle East indicated that patients from the United Arab Emirates, Saudi Arabia, Lebanon and Jordan were most commonly prescribed statin doses at a potency equivalent to $40 \mathrm{mg} /$ day and $80 \mathrm{mg} /$ day of simvastatin. ${ }^{13}$ This observation, along with the expanding indications for statins, are expected to lead to increases in the prevalence of statin-intolerant patients from the Arabian Gulf. ${ }^{14}$ Studies investigating this important issue are therefore warranted.

\section{Definitions and Diagnosis}

The NLA no longer uses the term 'statin-associated myopathy'; this was replaced by 'SaMAEs' in 2014. ${ }^{4}$ The new definitions utilise neuromuscular terminology for descriptions of myalgia and myopathy and require objective evidence of muscle inflammation (e.g. a skeletal muscle biopsy and/or magnetic resonance imaging) for a diagnosis of myositis. ${ }^{4}$ The guidelines also account for differences in age, gender and muscle mass when defining normal creatine kinase (CK) thresholds, with preferential use of the patient's own pre-statin CK levels, when available. Moreover, the guidelines acknowledge that clinical entities may overlap in clinical presentation. ${ }^{4}$ The EAS Consensus Panel, on the other hand, retains the general term 'statin-associated myopathy' and classifies the spectrum based on the presence or absence of statinassociated muscle symptoms, which cover a broader range of clinical presentations and CK levels. ${ }^{11}$ The CCWG introduced the concept of goal-inhibiting statin intolerance to emphasise the negative impact of these symptoms on achieving treatment goals. ${ }^{10}$

Statin therapy-associated myalgia is usually identified as a result of clinical characteristics, resolution with statin discontinuation and recurrence with rechallenge within an expected time limit; however, this is not true in all cases and concerns exist regarding reliable diagnosis of this disorder. ${ }^{12}$ Recent evidence from several clinical trials suggests that many patients who were previously considered to be statin intolerant based on clinical characteristics, were not actually intolerant. ${ }^{12,15,16}$ Although clinical myalgia scales exist, they have not yet been validated for diagnosis. ${ }^{4}$ In clinical practice, myalgia and/or mild CK elevations may persist for a lengthy period following statin discontinuation, although the mechanisms behind this delay are not clear. ${ }^{17}$ Several algorithms for diagnosing patients presenting with SaMAEs have been proposed. ${ }^{4,10}$

\section{Classification}

The classification and spectrum of SaMAEs is summarised in Table 1.,4,12,18-25 Based on pathogenesis, SaMAEs are classified into two major categories: toxic (i.e. nonautoimmune and self-limited) and autoimmune. $^{26}$ The clinical manifestations of toxic SaMAEs range from muscle pain to severe muscle damage leading to rhabdomyolysis. The 
Table 1: Classification and spectrum of statin-associated muscle adverse events ${ }^{1,4,12,18-25}$

\begin{tabular}{|c|c|c|c|}
\hline Type & Clinical presentation & Incidence/ prevalence & Long-term outcome \\
\hline Myalgia & $\begin{array}{l}\text { Unexplained muscle discomfort } \\
\text { without CK elevation, including } \\
\text { muscle aches, soreness, stiffness, } \\
\text { tenderness and exercise-related } \\
\text { cramps. }{ }^{4} \text { The pain is dull, aching, } \\
\text { widespread and involves the trunk } \\
\text { and proximal muscles. Calf and } \\
\text { forearm pain is less common and is } \\
\text { usually bilateral. }\end{array}$ & $\begin{array}{l}1-5 \% \text { in controlled } \\
\text { trials and } 11-29 \% \text { in } \\
\text { observational studies }^{4}\end{array}$ & $\begin{array}{l}\text { Myalgias are generally tolerable but can } \\
\text { become debilitating, requiring statin } \\
\text { withdrawal. The long-term outcome } \\
\text { is favourable. Symptoms improve or } \\
\text { full recovery occurs in the majority of } \\
\text { patients on cessation of statin therapy; } \\
\text { however, the condition can continue } \\
\text { beyond } 14 \text { months. }^{22}\end{array}$ \\
\hline Myopathy & $\begin{array}{l}\text { Muscle weakness (not due to pain } \\
\text { and/or CK elevation). A diagnosis is } \\
\text { made by the detection of proximal } \\
\text { weakness of grade } \leq 4 / 5 \text { and } \\
\text { standardised muscle testing with } \\
\text { confirmation by electromyography } \\
\text { and/or muscle biopsy. }{ }^{4} \text { Other causes } \\
\text { of muscle weakness should be } \\
\text { excluded. }\end{array}$ & $\approx 3 \%^{25}$ & $\begin{array}{l}\text { An annual assessment of muscle } \\
\text { strength is indicated in patients with } \\
\text { minimal symptoms without }>3 \times \text { ULN } \\
\text { CK elevations who elect to remain on } \\
\text { statin therapy. Serial assessment in } \\
\text { asymptomatic patients is unnecessary. } \\
\text { Among patients with persistent } \\
\text { symptoms after statin withdrawal, } \\
10 \% \text { have underlying neuromuscular }^{4} \text { disease. }^{23}\end{array}$ \\
\hline Myositis & $\begin{array}{l}\text { Muscle inflammation (determined } \\
\text { by skeletal muscle biopsy and/ } \\
\text { or magnetic resonance imaging), } \\
\text { commonly associated with muscle } \\
\text { pain and tenderness. }^{4}\end{array}$ & $\begin{array}{l}\text { Unknown as it is no } \\
\text { longer diagnosed } \\
\text { by clinical and CPK } \\
\text { criteria }\end{array}$ & $\begin{array}{l}\text { Can be toxic or autoimmune. The former } \\
\text { improves with statin discontinuation, } \\
\text { whereas in the latter only a few patients } \\
\text { improve with drug discontinuation; } \\
\text { for the remaining patients, the disease } \\
\text { is persistent or progressive despite } \\
\text { statin discontinuation. } .^{21,23,24} \text { The } \\
\text { autoimmune type is associated with } \\
\text { anti-HMGCR antibodies and requires } \\
\text { immunosuppressive therapy (steroids } \\
\text { and/or intravenous immunoglobulin). } .^{20}\end{array}$ \\
\hline Myonecrosis & $\begin{array}{l}\text { Elevated muscle enzymes or } \\
\text { consistently increased serum CK } \\
\text { levels. Muscle injury is graded as mild } \\
\text { ( }>3 \mathrm{x} \text { baseline untreated CK levels } \\
\text { or age-, race- and gender-adjusted } \\
\text { ULN), moderate ( } \geq 10 \mathrm{x} \text { baseline } \\
\text { untreated CK levels or age-, race- and } \\
\text { gender-adjusted ULN) or severe } \\
\text { ( } \geq 50 \text {-fold above baseline CK levels } \\
\text { or age-, race- and gender-adjusted } \\
\text { ULN; consistent with an absolute CK } \\
\text { concentration of } 10,000 \mathrm{IU} / \mathrm{L}){ }^{4}\end{array}$ & $\begin{array}{l}\text { Incidence is not well } \\
\text { defined as CK levels are } \\
\text { not routinely measured }\end{array}$ & $\begin{array}{l}\text { No data available for this pathological } \\
\text { entity in its full spectrum. }\end{array}$ \\
\hline $\begin{array}{l}\text { Clinical } \\
\text { rhabdomyolysis }\end{array}$ & $\begin{array}{l}\text { Severe myonecrosis, with } \\
\text { myoglobinuria and/or acute renal } \\
{\text { failure }{ }^{*} .}^{\text {. }}\end{array}$ & $\begin{array}{l}\text { Rare }(0.1-8.4 / 100,000 \\
\text { patients/year })^{21}\end{array}$ & $\begin{array}{l}\text { Carries a } 7.6 \% \text { risk of death with } 19.8 \% \\
\text { of patients developing acute renal failure } \\
\text { and } 17 \% \text { developing renal dysfunction. } \\
\text { There is a } 5.2 \% \text { risk of dialysis in affected } \\
\text { patients. }{ }^{19}\end{array}$ \\
\hline
\end{tabular}

$C K=$ creatine kinase $U L N=$ upper limit of normal; $C P K=$ creatine phosphokinase; HMGCR = 3-hydroxy-3-methylglutaryl-coenzyme A reductase . *Increased serum creatinine levels of $>0.5 \mathrm{mg} / \mathrm{dL} .{ }^{4}$

muscle adverse events in patients with toxic SaMAEs stabilise and show marked improvement within 2-3 months following statin cessation. ${ }^{18}$ Until recently, SaMAEs referred to the nonautoimmune form. ${ }^{26}$

Autoimmune inflammatory myositis and/or necrotising myopathy, on the other hand, starts or persists even after drug discontinuation. ${ }^{27}$ This entity is very rare and is characterised clinically by myalgia, symmetrical proximal muscle weakness, universally persistently elevated creatine phosphokinase (CPK) levels in individuals with active disease (CPK $>2,000 \mathrm{IU} / \mathrm{L}$ or $>10$ times the upper limit of the normal range in nearly $90 \%$ of cases) and the presence of autoantibodies to 3-hydroxy-3-methylglutaryl- coenzyme A reductase (HMGCR), the pharmacological target of statins. ${ }^{20,24}$ The presence of muscle weakness is a characteristic feature. ${ }^{24}$ An algorithm for the evaluation of potential cases of statin-associated autoimmune myopathy has been proposed. ${ }^{24}$

In statin-associated autoimmune myositis or myopathy, skeletal muscle involvement is not associated with cutaneous or pulmonary involvement, as observed with other inflammatory myopathies. ${ }^{17}$ Spontaneous improvement has been reported in a few very mild SaMAE cases following discontinuation of the statin therapy. ${ }^{24}$ However, immunosuppressive medications are necessary in the majority of patients. ${ }^{24}$ Immunosuppression may attenuate the myopathy, allowing muscle regeneration to outpace muscle 
destruction, although it may not completely abolish the underlying pathophysiological processes in all cases. ${ }^{20,24}$ During follow-up, antibody titres are useful for assessing treatment response in affected patients. ${ }^{26}$

\section{Diagnostic Role of Anti-3- Hydroxy-3-Methylglutaryl- Coenzyme A Reductase Autoantibodies}

In patients with SaMAEs, autoantibodies to HMGCR are highly specific for autoimmune myositis or myopathy and have not been detected to date in asymptomatic patients or patients with selflimited SaMAEs, including myalgia, weakness, mild asymptomatic CK elevations or severe self-limited myopathy or rhabdomyolysis. ${ }^{28,29}$ A positive test for anti-HMGCR autoantibodies strongly supports the presence of an autoimmune process, while an alternative diagnosis should be considered if the test is negative. ${ }^{24}$ However, anti-HMGCR antibodies are not pathognomonic for statin-related autoimmune myositis or myopathy; in the largest cohort studied to date, one-third of patients who were positive for antiHMGCR had autoimmune myositis or myopathy due to various causes. ${ }^{24}$ In general, the risk of antibody development is higher among individuals with prior statin exposure and those positive for human leukocyte antigen D-related (HLA-DR) 11; Limaye et al. found that $42 \%$ of statin-naive HLA-DR 11 subjects had detectable antibodies, which increased to $90 \%$ following statin exposure. ${ }^{27}$

Several laboratory techniques have been developed to detect anti-HMCGR autoantibodies, including the enzyme-linked immunosorbent assay (ELISA), addressable laser bead immunoassay and immunoblotting. ${ }^{17}$ Screening for anti-HMGCR autoantibodies via ELISA has achieved a sensitivity and specificity of $94.4 \%$ and $99.3 \%$, respectively. ${ }^{28}$ False-positive results on commercial ELISAs (0.7\%) are commonly due to the anti-cortactin antibody, another recently described myositis-associated antibody. ${ }^{17,24}$ Confirmation of positive ELISA samples by immunoprecipitation or immunoblotting is mandatory. ${ }^{17,30}$ The negative predictive value of ELISA in an unselected population was greater than 0.999; in a specialised myositis clinic, it was estimated at $0.996 .^{28}$ Therefore, a negative HMGCR ELISA result, regardless of clinical setting, means that it is very unlikely that a patient has an anti-HMGCR autoimmune myopathy requiring immunosuppressive therapy. ${ }^{28}$ To avoid erroneous diagnoses, only patients with markedly elevated muscle enzyme levels should be tested for these autoantibodies. ${ }^{24}$
Table 2: Risk factors for statin-induced myopathy $y^{8,21,33,34}$

\begin{tabular}{|c|c|}
\hline Patient-related factors & $\begin{array}{l}\text { Drug interaction- } \\
\text { related factors }\end{array}$ \\
\hline $\begin{array}{l}\text { Advanced age (especially }>80 \\
\text { years old) }\end{array}$ & $\begin{array}{l}\text { Gemfibrozil } \\
\text { (contraindicated } \\
\text { with statins) }\end{array}$ \\
\hline Female & $\begin{array}{l}\text { Red yeast rice } \\
\text { (contraindicated } \\
\text { with statins) }\end{array}$ \\
\hline Low BMI & Niacin (limit to $1 \mathrm{~g} /$ day) \\
\hline Asian ethnicity & Macrolide antibiotics \\
\hline Presence of renal disease & Azole antifungals \\
\hline Presence of hepatic disease & Protease inhibitors \\
\hline Untreated hypothyroidism & $\begin{array}{l}\text { Large quantities of } \\
\text { grapefruit juice }\end{array}$ \\
\hline Low vitamin D levels & $\begin{array}{l}\text { Nefazodone } \\
\text { (discontinued } \\
\text { antidepressant) }\end{array}$ \\
\hline Hypertension & $\begin{array}{l}\text { Cyclosporine (avoid } \\
\text { simvastatin, lovastatin } \\
\text { and atorvastatin) }\end{array}$ \\
\hline Diabetes mellitus & Verapamil/diltiazem \\
\hline Biliary tract obstruction & Warfarin \\
\hline $\begin{array}{l}\text { Personal or family history } \\
\text { of SaMAEs }\end{array}$ & Digoxin \\
\hline Family history of myopathy & Amiodarone \\
\hline $\begin{array}{l}\text { Genetic polymorphisms of the } \\
\text { CYP isozymes }\end{array}$ & $\begin{array}{l}\text { Ticagrelor (avoid } \\
\text { simvastatin) }\end{array}$ \\
\hline $\begin{array}{l}\text { Inflammatory or inherited } \\
\text { metabolic muscle disease } \\
\text { (e.g. McArdle's disease or } \\
\text { carnitine palmitoyltransferase } \\
\text { II deficiency) }\end{array}$ & Colchicine \\
\hline Strenuous exercise & Fusidic acid \\
\hline \multirow{4}{*}{$\begin{array}{l}\text { Surgery with severe metabolic } \\
\text { demands }\end{array}$} & Antipsychotics \\
\hline & $\begin{array}{l}\text { Alcohol abuse } \\
\text { (independently } \\
\text { predisposes to myopathy) }\end{array}$ \\
\hline & $\begin{array}{l}\text { Drug abuse (e.g. cocaine, } \\
\text { amphetamines or heroin) }\end{array}$ \\
\hline & High statin dose \\
\hline
\end{tabular}

$B M I=$ body mass index; SaMAEs = statin-associated muscle adverse events; $C Y P=$ cytochrome P450.

\section{Muscle Biopsy Findings}

Muscle biopsy findings vary among patients with SaMAEs. In one study, vacuolation of the T-tubular system with intact sarcolemmas was noted in the lesions of $56.8 \%$ of symptomatic patients with myalgia, weakness and cramps. ${ }^{31}$ This pathology may occur without CKelevations as the muscle fibre damage is largely restricted to the intracellular space while the 
intact lateral sarcolemma prevents CK leakage. Similar biopsy findings have been observed in asymptomatic patients as well. ${ }^{32}$ In cases of toxic necrotising myopathy, muscle fibre necrosis with prominent phagocytosis and small basophilic regenerating fibres have been observed in patients with elevated serum CK levels and weakness or myalgia; these patients did not have detectable HMGCR antibodies. ${ }^{18}$

In anti-HMGCR clinical syndrome, autoimmune inflammatory myositis and/or necrotising myopathy is observed. ${ }^{17}$ Necrotising myopathy is a characteristic pathological pattern consisting of scattered muscle fibre necrosis and regeneration, macrophage infiltrates, a few endomysial inflammatory cells (including cluster of differentiation [CD] 4+ and CD8+ T cells and plasmacytoid dendritic cells) and sarcolemmal complement deposition on the surface of non-necrotic muscle fibres. ${ }^{17}$ Some patients have predominantly autoimmune necrotising myopathy, which is characterised by necrotic muscle fibre infiltrating macrophages without inflammation, while the myositis subtype exhibits greater inflammatory cell infiltration. ${ }^{25}$ The two conditions likely represent one pathophysiological spectrum rather than separate entities and transformation has been reported on consecutive histological biopsies. ${ }^{25}$ It is important to emphasise that this entity is very rare; however, while general practitioners may not come across such cases in practice, they must remain vigilant regarding the basic principles and features of the syndrome.

\section{Risk Factors}

Risk factors for SaMAEs are shown in Table 2. ${ }^{8,21,33,34}$ Attention to these factors may be the best way to minimise the risk of muscle injuries, which are reported with all marketed statins. ${ }^{33}$ The highest risk of developing an SaMAE is with $80 \mathrm{mg}$ of simvastatin (18.2\%); therefore, this dose is better avoided. $^{8,35}$ Atorvastatin, pravastatin and fluvastatin (80 mg) have lower SaMAE risks (14.9\%, 10.9\% and $5.1 \%$, respectively) and are better tolerated. ${ }^{35,36}$ Drug interactions vary with statin type and dose; specific statin-drug interactions and contraindications have been previously reviewed in more detail. ${ }^{34}$

\section{Management of Dyslipidaemia}

In the management of dyslipidaemia among patients with SaMAEs, LDL-C reduction using evidence-based therapies to nationally-supported guideline-based targets is the optimal goal. ${ }^{7,10}$ The NLA/ACC/American Heart Association guidelines advise clinicians to reinforce the importance of adherence to statins and lifestyle changes; however, high-risk patients who are completely statin-intolerant or tolerant only at a lower-than-recommended statin intensity may be considered for non-statin cholesterol-lowering (NSCL) therapy. ${ }^{3,7}$ Drugs that have demonstrated ASCVD risk reduction benefits outweighing the potential for adverse events and drug-drug interactions are recommended, while addressing patient risks and preferences. ${ }^{36}$ It is important to exclude risk factors for SaMAEs and non-side-effect-related causes for discontinuation, such as insurance-related or financial causes and patient misconceptions regarding duration of therapy and the benefit-to-adverse effects ratio. ${ }^{3,37}$ In mild cases, the decision to continue treatment with statins belongs to the patient, aided by effective communication from the clinician. ${ }^{3}$

\section{STEP 1: STATIN RECHALLENGE}

Among patients with SaMAEs, 92.2\% can tolerate a second statin upon rechallenge, approximately 50\% can tolerate the original statin-occasionally with increases in dose-and up to $72.5 \%$ can successfully tolerate a third statin. ${ }^{37,38}$ Tolerance is improved when doses of a lower potency are prescribed. ${ }^{4}$ Stein et al. reported that $97 \%$ of patients with a history of SaMAEs tolerated switching to $80 \mathrm{mg}$ of daily fluvastatin, which reduced LDL-C levels by $32.8 \%{ }^{39}$ Figure 1 outlines recommended steps to approaching statin rechallenge among patients with SaMAEs.

Non-daily regimens include every other day, twice weekly and weekly dosing. ${ }^{40}$ Rosuvastatin and atorvastatin have long half-lives which makes them suitable for non-daily dosing. ${ }^{4}$ Rosuvastatin every other day has been reported to lower LDL-C levels by $40.9 \%$ at a dose of $20 \mathrm{mg}$, by $39 \%$ at $10 \mathrm{mg}$ and by $34 \%$ at a mean dose of $5.6 \mathrm{mg}$ (range: $2.5-10 \mathrm{mg}$ ). ${ }^{40,41}$ Additionally, atorvastatin every other day decreases LDL-C levels by $23 \%$ in comparison to $39 \%$ with daily dosing. With $20 \mathrm{mg}$ of lovastatin every other day, LDL-C levels were reduced by $21 \%$ and the drug was tolerated by $98 \%$ of the studied subjects. ${ }^{40}$ A total of 5-10 mg of rosuvastatin twice weekly significantly decreased LDL-C levels by $26 \%$, whereas changing doses of simvastatin from 10-20 mg daily to $40-80 \mathrm{mg}$ twice weekly was not effective in reducing LDL-C levels. Weekly doses of 5-20 mg of rosuvastatin decreased LDL-C levels by $6-62 \%$ in a small series. ${ }^{40}$ Overall, non-daily regimens are better tolerated compared to daily dosing, but result in lower LDL-C reductions. ${ }^{40}$ Nonetheless, even modest LDL-C reductions are thought to be useful in improving long-term outcomes; therefore, aiming for the highest 


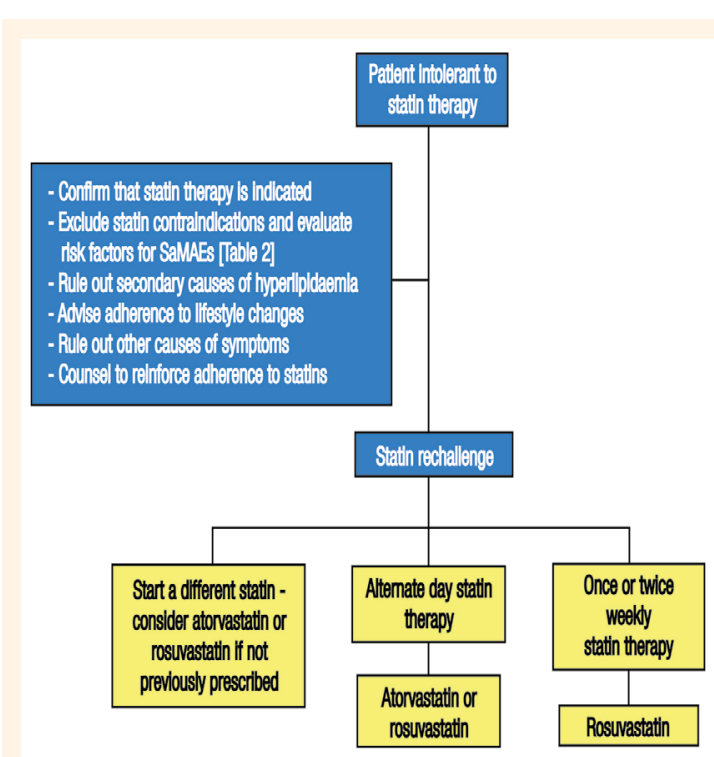

Figure 1: Flowchart outlining the first step (statin rechallenge) of recommended cholesterol-lowering therapy for patients with statin-associated muscle adverse events.

SaMAEs = statin-associated muscle adverse events.

tolerated dose is a reasonable endpoint. ${ }^{4}$ It is important to note, however, that while non-daily regimens are better tolerated, their use does not eliminate the possibility of on-going muscle pathology existing in the absence of clinical symptoms. ${ }^{30}$

\section{STEP 2: ADDITION/SUBSTITUTION OF NON-STATIN CHOLESTEROL- LOWERING DRUGS}

While NSCL monotherapy has been found to improve major cardiovascular endpoints, the evidence for its combination with statins has been consistently inadequate, except with ezetimibe. ${ }^{5}$ In addition, NSCLD monotherapy has been found to result in lower LDL-C reductions and is not without adverse effects. ${ }^{42}$ Ezetimibe is well tolerated but may cause nausea and bloating. ${ }^{43}$ When added to simvastatin therapy, it has resulted in incremental LDL-C lowering and an absolute risk reduction of $2 \%$ in the rate of cardiovascular mortality, myocardial infarction or stroke over a seven-year follow-up. ${ }^{5}$ Combined ezetimibe/atorvastatin, on the other hand, has resulted in lower LDL-C levels and greater coronary plaque regression than atorvastatin alone. ${ }^{44}$ Bile acid sequestrants (e.g. cholestyramine, colestipol and colesevelam) have been found to decrease LDL-C levels by approximately $15 \% .^{7}$ A combination of ezetimibe/ colesevelam has reduced LDL-C levels by $42 \%$ with no reports of discontinuation due to adverse events. ${ }^{45}$ In the Lipid Research Clinics Trial, cholestyramine decreased cardiovascular disease events by $25 \%{ }^{43}$
Niacin monotherapy reduced nonfatal myocardial infarctions by $27 \%$ and cerebrovascular events by $26 \%$ at a six-year follow-up as well as resulted in an $11 \%$ relative reduction in all-cause mortality at 15 years compared to a placebo in one study. ${ }^{46}$ Moreover, niacin in combination with clofibrate significantly reduced overall mortality and ischaemic heart diseaserelated mortality in comparison to a placebo. ${ }^{46} \mathrm{~A}$ statin/niacin combination, on the other hand, did not result in incremental clinical benefits in patients with atherosclerotic disease despite LDL-C reduction and an increase in high-density lipoprotein cholesterol (HDL-C) levels. ${ }^{47,48}$ There is currently a lack of data on the safety, efficacy or tolerability of niacin in statinintolerant individuals. ${ }^{10}$

Fibrates decrease triglyceride levels and raise HDL-C levels. ${ }^{49}$ However, cardiovascular disease outcomes with fibrate monotherapy have been mixed. Post hoc subgroup analyses in monotherapy studies have suggested the beneficial effects of fibrate therapy in subjects with high triglyceride levels, with or without low HDL-C levels. ${ }^{49}$ There is also evidence for a reduction in cardiovascular disease risk with fibrates, particularly among patients with diabetes and metabolic syndrome. ${ }^{8,43}$ However, doubling the statin dose yields a greater LDL-C reduction compared to the addition of fibrate therapy. ${ }^{50}$ Moreover, statin/ fibrate combinations do not reduce the rate of fatal cardiovascular events, nonfatal myocardial infarctions or nonfatal strokes compared with simvastatin monotherapy; however, there is a trend of cardiovascular disease event reduction $(P=0.057)$ with a statin/fibrate combination in patients with high triglyceride and low HDL-C levels. ${ }^{51}$ The interaction between gemfibrozil and statins is known to increase statin toxicity due to the inhibition of cytochrome P4502C8 and organic anion-transporting polypeptide 1B1 by gemfibrozil and its glucuronide, leading to increased plasma statin concentrations. ${ }^{52}$ On the other hand, the coadministration of statin with fenofibrate among patients with combined hyperlipidaemia is safe, although attention to factors predisposing to statin toxicity is always warranted when statins are used as either a monotherapy or in combination with other drugs. ${ }^{10,53}$

Monoclonal antibodies against PCSK9 have shown good efficacy and tolerability in patients with statin intolerance. At 12 weeks, evolocumab was found to reduce LDL-C levels by $53-56 \%$ compared to $15-18 \%$ with ezetimibe. ${ }^{6}$ Alirocumab resulted in an absolute LDL-C reduction of $84 \mathrm{mg} / \mathrm{dL}$ and had the lowest muscle-related adverse event rate of $33 \%$ versus $41 \%$ with ezetimibe $(P=0.10)$ and $46 \%$ with atorvastatin 


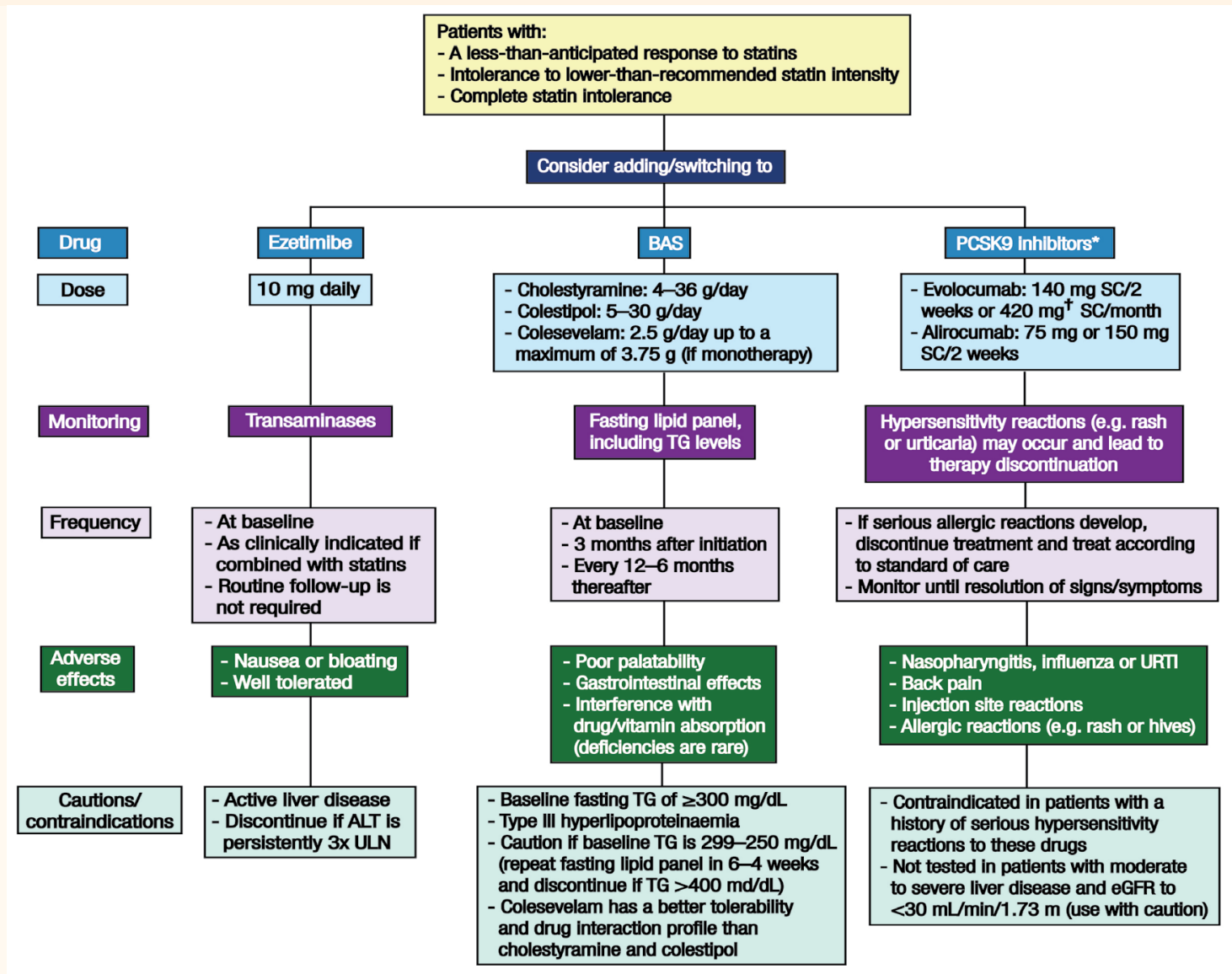

Figure 2: Flowchart outlining the second step (addition or substitution of non-statins) of recommended cholesterollowering therapy in patients with statin-associated muscle adverse events.

BAS = bile acid sequestrants; $P C S K 9$ = proprotein convertase subtilisin $/$ kexin type 9; $S C$ = subcutaneously; $T G$ = triglycerides; URTI = upper respiratory tract infection; $A L T$ = alanine aminotransferase; $U L N=$ upper limit of normal; eGFR = estimated glomerular filtration rate.

"Approved for use as an adjunct to diet and maximally-tolerated statin therapy in adult patients with heterozygous or homozygous familial hypercholesterolaemia and patients with clinical atherosclerotic cardiovascular disease who require additional lowering of their low-density lipoprotein cholesterol levels. ${ }^{\dagger}$ Three evolucumab injections consecutively within 30 minutes.

$(P=0.04) \cdot{ }^{6}$ Preliminary evidence on the efficacy of PCSK9 inhibitors combined with statins shows reduced cardiovascular outcomes. ${ }^{49}$ However, the safety and tolerability profile of PCSK9 inhibitors remains to be proven; this is the aim of large trials of cardiovascular outcomes currently underway. ${ }^{6}$ If the benefits of PCSK9 inhibitors follow a similar trend to statins, major vascular events could be reduced by up to $40-50 \%$ in high-risk patients. ${ }^{6}$ The use of PCSK9 inhibitors has been approved in Europe and North America as adjuncts to diet and maximally-tolerated statin therapy in adult patients with heterozygous or homozygous familial hypercholesterolaemia and patients with clinical ASCVD who require additional lowering of LDL-C levels. ${ }^{49,54,55}$

Lomitapide and mipomersen have been recently approved in the USA for the treatment of familial hypercholesterolaemia; these drugs substantially reduce LDL-C levels via distinct low-density lipoprotein receptor-independent mechanisms. ${ }^{49}$ Other potential therapeutic options include plant sterol esters or stanol esters (found in margarines), viscous fibre (found in oat bran, legumes and psyllium) and the dietary substitution of mono- or polyunsaturated fats for trans-unsaturated or -saturated fats. ${ }^{3}$

Following statin rechallenge, the choice of NSCL drug in patients deemed to have partial or complete intolerance to statins is governed by the degree of LDL-C reduction required to achieve a prespecified goal. Figure 2 presents the recommended steps in prescribing non-statins to patients with SaMAEs and details possible non-statin drug choices. Priority should be given to agents with proven cardiovascular outcomes, particularly ezetimibe, bile acid sequestrants or both. $4,7,8,33,36,43,54,55$ It has been suggested that if the patient is within $20 \%$ of their clinical LDL-C goal, then ezetimibe is preferred; in contrast, for patients who need a $>20 \%$ reduction in their LDL-C levels, the choice is between multiple standard agents added sequentially (e.g. ezetimibe, a bile acid sequestrant and niacin), PCSK9 inhibitors, lomitapide or mipomersen (for patients with homozygous familial 
hypercholesterolaemia), apheresis (if available) or complex polypharmacy. ${ }^{10}$ It is important to keep in mind that non-daily statin doses and the combination of statin plus non-statin therapy may provide treatment alternatives and result in LDL-C reductions similar to those seen with high-dose statin regimens. ${ }^{4}$

\section{POLYPHARMACY CHALLENGES}

Patients with clinical ASCVD who have lower LDL-C goals and those with significant baseline LDL-C elevations (i.e. familial hyperlipidaemia) may pose a treatment challenge and require polypharmacy to achieve their prespecified LDL-C goals. While ezetimibe is well tolerated, the addition of a resin or niacin may not be tolerated in all patients. Since the maximal LDL-C reduction which can be achieved with ezetimibe is approximately $20 \%$, other safe and effective lipid-lowering agents for patients who require greater LDL-C reductions are necessary. ${ }^{7}$ The use of PCSK9 inhibitors is governed by cost and local policies. ${ }^{56}$ It is important to emphasise that PCSK9 inhibitors are approved only as adjuncts to statins unless the patient is completely intolerant. ${ }^{48,53,54}$

\section{Conclusion}

Cardiovascular benefits are strongly linked to reductions in LDL-C levels, as long as proven and safe LDLC-lowering agents are used. While most SaMAEs are mild and reversible, a subgroup of patients treated with statins may develop autoimmune inflammatory myositis or necrotising myopathy which does not resolve with statin discontinuation and requires immunosuppressive therapy. Statin rechallenge is successful in the majority of cases and is the first choice of therapy; in these instances, the maximal tolerated dose should be used and continued-even if outcomes are modest-in order to meet nationally-supported guideline-based LDL-C goals and reduce the patient's cardiovascular risk. Nevertheless, evidence regarding the effectiveness of NSCL therapy is accumulating and ezetimibe, bile acid sequestrants and PCSK9 inhibitors are currently the most effective statin alternatives.

\section{References}

1. Antonopoulos AS, Margaritis M, Lee R, Channon K, Antoniades C. Statins as anti-inflammatory agents in atherogenesis: Molecular mechanisms and lessons from the recent clinical trials. Curr Pharm Des 2012; 18:1519-30. doi: 10.2174/ 138161212799504803.
2. Cholesterol Treatment Trialists' (CTT) Collaboration; Baigent C, Blackwell L, Emberson J, Holland LE, Reith C, et al. Efficacy and safety of more intensive lowering of LDL cholesterol: A meta-analysis of data from 170,000 participants in 26 randomised trials. Lancet 2010; 376:1670-81. doi: 10.1016/ S0140-6736(10)61350-5.

3. Guyton JR, Bays HE, Grundy SM, Jacobson TA; The National Lipid Association Statin Intolerance Panel. An assessment by the Statin Intolerance Panel: 2014 update. J Clin Lipidol 2014; 8:S72-81. doi: 10.1016/j.jacl.2014.03.002.

4. Rosenson RS, Baker SK, Jacobson TA, Kopecky SL, Parker BA; The National Lipid Association's Muscle Safety Expert Panel. An assessment by the Statin Muscle Safety Task Force: 2014 update. J Clin Lipidol 2014; 8:S58-71. doi: 10.1016/j. jacl.2014.03.004.

5. Cannon CP, Blazing MA, Giugliano RP, McCagg A, White JA, Theroux $\mathrm{P}$, et al. Ezetimibe added to statin therapy after acute coronary syndromes. N Engl J Med 2015; 372:2387-97. doi: 10.1056/NEJMoa1410489.

6. Giugliano RP, Sabatine MS. Are PCSK9 inhibitors the next breakthrough in the cardiovascular field? J Am Coll Cardiol 2015; 65:2638-51. doi: 10.1016/j.jacc.2015.05.001.

7. Writing Committee; Lloyd-Jones DM, Morris PB, Ballantyne CM, Birtcher KK, Daly DD Jr, et al. 2016 ACC expert consensus decision pathway on the role of non-statin therapies for LDLcholesterol lowering in the management of atherosclerotic cardiovascular disease risk: A report of the American College of Cardiology Task Force on clinical expert consensus documents. J Am Coll Cardiol 2016; 68:92-125. doi: 10.1016/j. jacc.2016.03.519.

8. Mancini GB, Baker S, Bergeron J, Fitchett D, Frohlich I, Genest J, et al. Diagnosis, prevention, and management of statin adverse effects and intolerance: Proceedings of a Canadian Working Group Consensus Conference. Can I Cardiol 2011; 27:635-62. doi: 10.1016/j.cjca.2011.05.007.

9. Mancini GB, Tashakkor AY, Baker S, Bergeron J, Fitchett D, Frohlich J, et al. Diagnosis, prevention, and management of statin adverse effects and intolerance: Canadian Working Group Consensus update. Can J Cardiol 2013; 29:1553-68. doi: 10.1016/j.cjca.2013.09.023.

10. Mancini GB, Baker S, Bergeron J, Fitchett D, Frohlich J, Genest J, et al. Diagnosis, prevention, and management of statin adverse effects and intolerance: Canadian Consensus Working Group update (2016). Can J Cardiol 2016; 32:S35-65. doi: 10.1016/j. cjca.2016.01.003.

11. Stroes ES, Thompson PD, Corsini A, Vladutiu GD, Raal FJ, Ray KK, et al. Statin-associated muscle symptoms: Impact on statin therapy - European Atherosclerosis Society Consensus Panel statement on assessment, aetiology and management. Eur Heart J 2015; 36:1012-22. doi: 10.1093/eurheartj/ehv043.

12. Nissen SE, Stroes E, Dent-Acosta RE, Rosenson RS, Lehman SJ, Sattar N, et al. Efficacy and tolerability of evolocumab vs ezetimibe in patients with muscle-related statin intolerance: The GAUSS-3 randomized clinical trial. JAMA 2016; 315:1580-90. doi: 10.1001/jama.2016.3608.

13. Al Sifri SN, Almahmeed W, Azar S, Okkeh O, Bramlage P, Jünger $C$, et al. Results of the Dyslipidemia International Study (DYSIS)-Middle East: Clinical perspective on the prevalence and characteristics of lipid abnormalities in the setting of chronic statin treatment. PloS One 2014; 9:e84350. doi: 10.1371/ journal.pone.0084350.

14. Mahmood D, Jahan K, Habibullah K. Primary prevention with statins in cardiovascular diseases: A Saudi Arabian perspective. J Saudi Heart Assoc 2015; 27:179-91. doi: 10.1016/j. jsha.2014.09.004 
15. Joy TR, Monjed A, Zou GY, Hegele RA, McDonald CG, Mahon JL. N-of-1 (single-patient) trials for statin-related myalgia. Ann Intern Med 2014; 160:301-10. doi: 10.7326/M13-1921.

16. Moriarty PM, Thompson PD, Cannon CP, Guyton JR, Bergeron J, Zieve FJ, et al. Efficacy and safety of alirocumab vs ezetimibe in statin-intolerant patients, with a statin rechallenge arm: The ODYSSEY ALTERNATIVE randomized trial. J Clin Lipidol 2015; 9:758-69. doi: 10.1016/j.jacl.2015.08.006.

17. Selva-O'Callaghan A, Alvarado-Cardenas M, Marin A, PinalFernandez I. Statins and myositis: The role of anti-HMGCR antibodies. Expert Rev Clin Immunol 2015; 11:1277-9. doi: 10.1586/1744666X.2015.1102632.

18. Pasnoor M, Barohn RJ, Dimachkie MM. Toxic myopathies. Neurol Clin 2014; 32:647-70. doi: 10.1016/j.ncl.2014.04.009.

19. Holbrook A, Wright M, Sung M, Ribic C, Baker S. Statinassociated rhabdomyolysis: Is there a dose-response relationship? Can J Cardiol 2011; 27:146-51. doi: 10.1016/j. cjca.2010.12.024.

20. Mammen AL, Tiniakou E. Intravenous immune globulin for statin-triggered autoimmune myopathy. N Engl J Med 2015; 373:1680-2. doi: 10.1056/NEJMc1506163.

21. Alfirevic A, Neely D, Armitage J, Chinoy H, Cooper RG, Laaksonen $\mathrm{R}$, et al. Phenotype standardization for statininduced myotoxicity. Clin Pharmacol Ther 2014; 96:470-6. doi: $10.1038 /$ clpt.2014.121.

22. Armour R, Zhou L. Outcomes of statin myopathy after statin withdrawal. J Clin Neuromuscul Dis 2013; 14:103-9. doi: 10.1097/CND.0b013e3182852558.

23. Echaniz-Laguna A, Mohr M, Tranchant C. Neuromuscular symptoms and elevated creatine kinase after statin withdrawal. N Engl J Med 2010; 362:564-5. doi: 10.1056/NEJMc0908215.

24. Mammen AL. Statin-associated autoimmune myopathy. N Engl J Med 2016; 374:664-9. doi: 10.1056/NEJMra1515161.

25. Wu Y, Lach B, Provias JP, Tarnopolsky MA, Baker SK. Statinassociated autoimmune myopathies: A pathophysiologic spectrum. Can J Neurol Sci 2014; 41:638-47. doi: 10.1017/ cjn.2014.22.

26. Babu S, Li Y. Statin induced necrotizing autoimmune myopathy. J Neurol Sci 2015; 351:13-17. doi: 10.1016/j.jns.2015.02.042

27. Limaye V, Bundell C, Hollingsworth P, Rojana-Udomsart A, Mastaglia F, Blumbergs $\mathrm{P}$, et al. Clinical and genetic associations of autoantibodies to 3-hydroxy-3-methyl-glutaryl-coenzyme A reductase in patients with immune-mediated myositis and necrotizing myopathy. Muscle Nerve 2015; 52:196-203. doi: $10.1002 /$ mus. 24541 .

28. Mammen AL, Pak K, Williams EK, Brisson D, Coresh J, Selvin E, et al. Rarity of anti-3-hydroxy-3-methylglutaryl-coenzyme-A reductase antibodies in statin users, including those with self-limited musculoskeletal side effects. Arthritis Care Res (Hoboken) 2012; 64:269-72. doi: 10.1002/acr.20662.

29. Floyd JS, Brody JA, Tiniakou E, Psaty BM, Mammen A. Absence of anti-HMG-CoA reductase autoantibodies in severe selflimited statin-related myopathy. Muscle Nerve 2016; 54:142-4. doi: $10.1002 /$ mus.25127.

30. Mammen AL, Chung T, Christopher-Stine L, Rosen P, Rosen A, Doering KR, et al. Autoantibodies against 3-hydroxy3-methylglutaryl-coenzyme A reductase in patients with statinassociated autoimmune myopathy. Arthritis Rheum 2011; 63:713-21. doi: 10.1002/art.30156

31. Mohaupt MG, Karas RH, Babiychuk EB, Sanchez-Freire V, Monastyrskaya K, Iyer L, et al. Association between statinassociated myopathy and skeletal muscle damage. CMAJ 2009; 181:E11-18. doi: 10.1503/cmaj.081785.

32. Draeger A, Monastyrskaya $\mathrm{K}$, Mohaupt M, Hoppeler $\mathrm{H}$, Savolainen H, Allemann C, et al. Statin therapy induces ultrastructural damage in skeletal muscle in patients without myalgia. J Pathol 2006; 210:94-102. doi: 10.1002/path.2018.
33. Rallidis LS, Fountoulaki K, Anastasiou-Nana M. Managing the underestimated risk of statin-associated myopathy. Int J Cardiol 2012; 159:169-76. doi: 10.1016/j.ijcard.2011.07.048

34. Kellick KA, Bottorff M, Toth PP; The National Lipid Association's Safety Task Force. A clinician's guide to statin drug-drug interactions. J Clin Lipidol 2014; 8:S30-46. doi: 10.1016/j.jacl.2014.02.010.

35. Bruckert E, Hayem G, Dejager S, Yau C, Bégaud B. Mild to moderate muscular symptoms with high-dosage statin therapy in hyperlipidemic patients: The PRIMO study. Cardiovasc Drugs Ther 2005; 19:403-14. doi: 10.1007/s10557-005-5686-z.

36. Stone NJ, Robinson JG, Lichtenstein AH, Bairey Merz CN, Blum CB, Eckel RH, et al. 2013 ACC/AHA guideline on the treatment of blood cholesterol to reduce atherosclerotic cardiovascular risk in adults: A report of the American College of Cardiology/American Heart Association Task Force on practice guidelines. Circulation 2014; 129:S1-45. doi: 10.1161/01.cir.0000437738.63853.7a.

37. Zhang H, Plutzky J, Skentzos S, Morrison, F, Mar P, Shubina M, et al. Discontinuation of statins in routine care settings: A cohort study. Ann Intern Med 2013; 158:526-34. doi: 10.7326/00034819-158-7-201304020-00004.

38. Neal RC, Ferdinand KC, Ycas J, Miller E. Relationship of ethnic origin, gender, and age to blood creatine kinase levels. Am J Med 2009; 122:73-8. doi: 10.1016/j.amjmed.2008.08.033.

39. Stein EA, Ballantyne CM, Windler E, Sirnes PA, Sussekov A, Yigit Z, et al. Efficacy and tolerability of fluvastatin XL $80 \mathrm{mg}$ alone, ezetimibe alone, and the combination of fluvastatin XL $80 \mathrm{mg}$ with ezetimibe in patients with a history of musclerelated side effects with other statins. Am J Cardiol 2008; 101:490-6. doi: 10.1016/j.amjcard.2007.09.099.

40. Elis A, Lishner M. Non-every day statin administration: A literature review. Eur J Intern Med 2012; 23:474-8. doi: 10.1016/j.ejim.2012.02.006.

41. Dulay D, LaHaye SA, Lahey KA, Day AG. Efficacy of alternate day versus daily dosing of rosuvastatin. Can J Cardiol 2009; 25:e28-31. doi: 10.1016/S0828-282X(09)70480-5.

42. Mampuya WM, Frid D, Rocco M, Huang J, Brennan DM, Hazen SL, et al. Treatment strategies in patients with statin intolerance: The Cleveland Clinic experience. Am Heart J 2013; 166:597-603. doi: 10.1016/j.ahj.2013.06.004.

43. Ewang-Emukowhate M, Wierzbicki AS. Lipid-lowering agents. J Cardiovasc Pharmacol Ther 2013; 18:401-11. doi: $10.1177 / 1074248413492906$.

44. Tsujita K, Sugiyama S, Sumida H, Shimomura H, Yamashita T, Yamanaga $\mathrm{K}$, et al. Impact of dual lipid-lowering strategy with ezetimibe and atorvastatin on coronary plaque regression in patients with percutaneous coronary intervention: The multicenter randomized controlled PRECISE-IVUS trial. J Am Coll Cardiol 2015; 66:495-507. doi: 10.1016/j.jacc.2015.05.065.

45. Zema MJ. Colesevelam $\mathrm{HCl}$ and ezetimibe combination therapy provides effective lipid-lowering in difficult-to-treat patients with hypercholesterolemia. Am J Ther 2005; 12:306-10.

46. Al-Mohaissen MA, Pun SC, Frohlich JJ. Niacin: From mechanisms of action to therapeutic uses. Mini Rev Med Chem 2010; 10:204-17. doi: 10.2174/138955710791185046.

47. AIM-HIGH Investigators; Boden WE, Probstfield JL, Anderson T, Chaitman BR, Desvignes-Nickens P, et al. Niacin in patients with low HDL cholesterol levels receiving intensive statin therapy. N Engl J Med 2011; 365:2255-67. doi: 10.1056/ NEJMoa1107579.

48. HPS2-THRIVE Collaborative Group; Landray MJ, Haynes R, Hopewell JC, Parish S, Aung T, et al. Effects of extended-release niacin with laropiprant in high-risk patients. N Engl J Med 2014; 371:203-12. doi: 10.1056/NEJMoa1300955. 
49. Hegele RA, Gidding SS, Ginsberg HN, McPherson R, Raal FJ Rader DJ, et al. Nonstatin low-density lipoprotein-lowering therapy and cardiovascular risk reduction: Statement from ATVB Council. Arterioscler Thromb Vasc Biol 2015; 35:2269-80. doi: 10.1161/ATVBAHA.115.306442.

50. Ouwens MJ, Nauta J, Ansquer JC, Driessen S. Systematic literature review and meta-analysis of dual therapy with fenofibrate or fenofibric acid and a statin versus a double or equivalent dose of statin monotheraphy. Curr Med Res Opin 2015; 31:2273-85. doi: 10.1185/03007995.2015.1098597.

51. ACCORD Study Group; Ginsberg HN, Elam MB, Lovato LC, Crouse JR 3rd, Leiter LA, et al. Effects of combination lipid therapy in type 2 diabetes mellitus. N Engl J Med 2010; 362:1563-74. doi: 10.1056/NEJMoa1001282.

52. Neuvonen PJ, Niemi M, Backman JT. Drug interactions with lipid-lowering drugs: Mechanisms and clinical relevance Clin Pharmacol Ther 2006; 80:565-81. doi: 10.1016/j.clpt 2006.09.003.
53. Guo J, Meng F, Ma N, Li C, Ding Z, Wang H, et al. Meta-analysis of safety of the coadministration of statin with fenofibrate in patients with combined hyperlipidemia. Am J Cardiol 2012; 110:1296-301. doi: 10.1016/j.amjcard.2012.06.050.

54. Sanofi-aventis Canada Inc. Product monograph including patient medication information: PrPraluent ${ }^{\mathrm{Tm}}$. From: www. products.sanofi.ca/en/praluent.pdf Accessed: Jun 2016.

55. U.S. Food and Drug Administration. Highlights of prescribing information: REPATHA ${ }^{\mathrm{Tx}}$. From: www.accessdata.fda.gov/ drugsatfda_docs/label/2015/125522s000lbl.pdf Accessed: Jun 2016.

56. Bergeron N, Phan BA, Ding Y, Fong A, Krauss RM. Proprotein convertase subtilisin/kexin type 9 inhibition: A new therapeutic mechanism for reducing cardiovascular disease risk. Circulation 2015; 132:1648-66. doi: 10.1161/ CIRCULATIONAHA.115.016080. 